\title{
EL PATRIMONIO INMATERIAL DE CANARIAS COMO BIEN CULTURAL Y ALGUNOS COTEJOS AMERICANOS (LA ANTI- GUA GUATEMALA Y GUADALAJARA, MÉXICO)
}

\author{
Juan Sebastián López García* \\ Universidad de Las Palmas de Gran Canaria
}

\section{RESUMEN}

El patrimonio inmaterial es una categoría cada vez más considerada en la ampliación que ha ido adquiriendo en las últimas décadas el concepto bien cultural. En este trabajo se explican los contenidos relativos al patrimonio inmaterial en la nueva Ley de Patrimonio Cultural de Canarias (2019) y se expone el proceso de su valoración como bien de interés cultural en este archipiélago. Se hace un análisis del estado de la cuestión en cada una de las ocho islas con la relación de sus bienes culturales inmateriales protegidos y se plantean otros nuevos, con la conclusión de que hasta el momento han sido considerados más un recurso turístico que propiamente un patrimonio cultural, además de presentar una desigual distribución en el territorio con grandes diferencias entre islas. Tras el análisis de Canarias se seleccionan dos casos americanos, uno de Guatemala y otro de México (La Antigua Guatemala y Guadalajara), para cotejar aspectos del patrimonio inmaterial con una visión más amplia en el ámbito internacional cultural hispano.

Palabras clave: bienes culturales, patrimonio inmaterial, patrimonio intangible, Canarias, legislación, Guadalajara (México), La Antigua Guatemala.

\footnotetext{
THE INTANGIBLE HERITAGE OF THE CANARY ISLANDS AS A "BIEN CULTURAL" (CULTURAL ASSET) AND SOME COMPARISONS WITH THE AMERICAN CONTINENT (LA ANTIGUA GUATEMALA AND GUADALAJARA, MEXICO)
}

\section{Abstract}

Intangible heritage is a category increasingly considered in the expansion that the concept of Cultural Heritage has acquired in recent decades. This paper explains the contents related to intangible heritage in the new Ley de Patrimonio Cultural de Canarias (2019) (Cultural Heritage of the Canary Islands Act), and the process of its valuation as an asset of cultural interest in this archipelago is presented. The current situation is analyzed in each of the eight Islands, and some new cultural assets are proposed, with the conclusion that up to now they have been considered more a tourist resource than cultural heritage, and also that they present an unequal distribution in the territory, with great differences between islands. After the analysis of the Canary Islands, two American continent cases were selected, one from Guatemala and the other from Mexico (La Antigua Guatemala and Guadalajara), to compare aspects of intangible heritage with a broader vision in the international Hispanic cultural field.

KeYwords: cultural assets, inmaterial heritage, intangible heritage, Canary Islands, legislation, Guadalajara (Mexico), La Antigua Guatemala. 


\section{INTRODUCCIÓN}

El patrimonio intangible o inmaterial es un aspecto cada vez más valorado del legado cultural que evidencia de forma muy particular la amplitud que ha ido adquiriendo ese concepto en las últimas décadas. Esta tendencia se ha visto claramente en las declaraciones de los últimos años de Patrimonio de la Humanidad, donde esta categoría tiene una mayor presencia, unido al aumento de la incorporación de bienes localizados fuera de Europa, dada la alta representatividad que ya tiene nuestro continente en la lista mundial. En este contexto irá asumiendo un mayor protagonismo en los próximos años el binomio bienes inmateriales/América.

Los bienes culturales intangibles suponen una enorme riqueza cultural que puede constituir un aporte único que singulariza a determinados lugares, incluso como patrimonio vivo. La variedad y calidad de sus expresiones permiten itinerarios en el tiempo y el espacio y son imprescindibles en la valoración integral del legado de los pueblos, especialmente en su capacidad de aportar identidad. El acervo inmaterial, por sus propias características, tiene unas especificidades que lo hacen vulnerable a muchos agentes y por tanto requiere de una atención muy particular y diferenciada con respecto a otros tipos de bienes. Es llamativo que el patrimonio intangible se presenta cada vez más como un recurso artístico y turístico que tiene un gran poder de atracción por su propio carácter no duradero, en particular el «arte efímero", que cuenta con presencia preferente en los centros históricos, donde son manifestaciones muy arraigadas en su patrimonio cultural.

El patrimonio inmaterial paulatinamente ha ido adquiriendo importancia como expresión diferenciada dentro del contexto general de los bienes culturales. En este recorrido, María Pía Timón Tiemblo ha ofrecido un estado de la cuestión del concepto trazado por la Unesco en las últimas décadas y su aceptación en la legislación española y autonómica ${ }^{1}$. En su repaso, Timón explicó que a partir del renovado concepto bien cultural, donde se contempla todo lo que pertenece a la historia de la civilización (1974), años más tarde la Declaración de México (1982) redefine el concepto de patrimonio cultural con los aportes no solo tangibles, sino también

* Profesor titular de Historia del Arte, Departamento de Arte, Ciudad y Territorio. Escuela de Arquitectura. Campus de Tafira. Universidad de Las Palmas de Gran Canaria (ULPGC). Email: juansebastian.lopez@ulpgc.es.

1 Timón Tiemblo, María Pía: «El Plan Nacional como instrumento de salvaguarda del patrimonio inmaterial de España», conferencia, Teatro Consistorial, Gáldar, sábado 30 de noviembre de 2019. Timón Tiemblo es coordinadora del Plan Nacional de Salvaguarda del Patrimonio Cultural Inmaterial en el Ministerio de Cultura y Deporte (Gobierno de Espańa), Instituto del Patrimonio Cultural de España. La conferencia magistral fue de clausura del ciclo «Celso Martín de Guzmán (1946-1994). XXV ańos después». Véase también Martino Alba, Pilar: "La Bajada de la Virgen como Bien Inmaterial», y Crehuet i Serra, Eladi: «El Patrimonio Inmaterial de la UNESCO y las Fiestas Lustrales de Santa Cruz de La Palma», en Primer Congreso Internacional de la Bajada de la Virgen (Santa Cruz de La Palma, 27-30 de julio de 2017), libro de actas, edición de Manuel Poggio Capote y Víctor J. Hernández Correa, Breña Ata (La Palma), Cartas Diferentes Ediciones, 2017, pp. 129-142, 149-157. 
los intangibles, que luego recogería la Ley 16/1985, de Patrimonio Histórico Español, en su título vi (Patrimonio etnológico, conocimientos y actividades). Superadas las consideraciones más restrictivas anteriores, se fueron planteando otras disposiciones como la Recomendación Unesco sobre la Cultura Tradicional y Popular (1989), a la que unos pocos años después se suma la Declaración de Estambul sobre el Patrimonio Cultural Inmaterial (2002), respaldada por la III Mesa Redonda de Ministros de Cultura, la cual fue fundamental para introducir, difundir y afianzar el uso del término Patrimonio Cultural Inmaterial, tipo de legado que tiene en sus poseedores su principal fundamento, muy relacionado con el arraigo y la voluntad popular de mantenerlo. A la Declaración de Estambul siguió en 2003 la aprobación de la Convención sobre la Salvaguarda del Patrimonio Cultural Inmaterial, documento que unido a los aportes anteriores ha guiado los contenidos de la legislación que se ha desarrollado en España. En concreto, hay que destacar la Ley 10/2015 de Salvaguardia del Patrimonio Cultural Inmaterial, a la que han seguido leyes autonómicas que han integrado los nuevos conceptos como la Ley 5/2016 de Patrimonio Cultural de Galicia o alguna específica, siendo reflejo de ello la Ley 18/2019 de Salvaguardia del Patrimonio Cultural Inmaterial de las Islas Baleares. En esta misma línea se inserta la Ley 11/2019 sobre Patrimonio Cultural de Canarias, que se tratará en este artículo².

En el presente trabajo se van a trazar varias líneas que intentarán ofrecer algunos enfoques concretos del tema, pero teniendo en cuanta realidades de territorios diferentes, sin abrir demasiado el campo temático. El foco central estará en la consideración del patrimonio intangible como bien de interés cultural, es decir, su reconocimiento de protección oficial desde una posición que nos es conocida. Recientemente se ha aprobado la Ley 11/2019, de 25 de abril, de Patrimonio Cultural de Canarias ${ }^{3}$, donde el patrimonio inmaterial isleño queda incorporado con claridad en «los usos, representaciones, expresiones, conocimientos y técnicas que las comunidades, los grupos y, en algunos casos, los individuos reconozcan como parte integrante de su patrimonio cultural». En la misma se determina que los bienes inmateriales son susceptibles de ser declarados de interés cultural en virtud de poseer una o varias categorías en una enumeración de once ítems que incluyen distintos aspectos a título orientativo.

En el momento de su aprobación y entrada en vigor el 13 de junio de 2019, la comunidad autónoma contaba con una pequeña nómina de bienes inmateriales oficialmente protegidos, que lo fueron en virtud de la anterior Ley 4/1999, de 15 de marzo, de Patrimonio Histórico de Canarias, a pesar de que en la misma no contaba esa categoría con el desarrollo del actual texto legal. Estos bienes serán objeto de análisis según las diferentes islas, detectándose las tendencias de cada una y el panorama que actualmente ofrece esta nacionalidad y en paralelo se esbozarán bre-

\footnotetext{
2 Nuestro agradecimiento a María Pía Timón Tiemblo por facilitarnos el contenido de su conferencia.

3 Boletin Oficial de Canarias (BOC) núm. 90, lunes 13 de mayo de 2019.
} 
vemente las potencialidades insulares en aras de futuras actuaciones. Para abrir el horizonte de este fenómeno, tras la situación general canaria se considerarán aspectos del patrimonio intangible pertenecientes al municipio de La Antigua Guatemala (departamento de Sacatepéquez, República de Guatemala) y a la ciudad de Guadalajara (estado de Jalisco, México), lo que permitirá ampliar someramente la visión con otros dos ámbitos distintos vinculados por la hispanidad y su cultura común.

En suma, Canarias, con más de dos millones de habitantes, un despoblamiento rural notable y una fuerte incidencia del fenómeno turístico, presenta unos perfiles de vulnerabilidad del legado inmaterial distribuido en ocho islas ${ }^{4}$. La nueva Ley supone una oportunidad para analizar los bienes de este tipo que hasta el momento se han protegido y por tanto están identificados, pero también para reflexionar acerca de los que aún no están representados, la necesidad de salvaguardarlos y ponerlos en valor.

\section{LA LEY CANARIA DE PATRIMONIO CULTURAL Y LOS BIENES INMATERIALES}

Desde el punto de vista de este trabajo, la principal aportación de la Ley radica en su artículo 25 y el capítulo $v$, dedicado al patrimonio inmaterial, ya que el texto legal utiliza este concepto y no el de patrimonio intangible, que entendemos similares. El artículo 25 trata de la clasificación de los bienes de interés cultural inmateriales, que se podrán declarar con arreglo a una o varias categorías de la Ley: «a) Tradiciones y expresiones orales, incluidas las modalidades y particularidades lingüísticas del español hablado en Canarias, así como la toponimia tradicional como instrumento para la concreción de la denominación geográfica de los territorios. b) Cultura inmaterial de la emigración canaria. c) Artes del espectáculo. d) Usos sociales, rituales y actos festivos. e) Conocimientos y usos relacionados con la naturaleza, el cielo y la mar. f) Técnicas artesanales tradicionales. g) Gastronomía, elaboraciones culinarias y alimentación. h) Aprovechamientos específicos de los paisajes naturales. i) Formas de socialización colectiva y organizaciones. j) Manifestaciones sonoras, música y danza tradicional. k) Juegos y deportes autóctonos». En el artículo 106 define: «Concepto. Tendrán la consideración de patrimonio cultural inmaterial los usos, representaciones, expresiones, conocimientos y técnicas que las comunidades, los grupos, y, en algunos casos, los individuos reconozcan

${ }^{4}$ Buena parte del legado y patrimonio inmaterial del archipiélago son fiestas o forman parte de celebraciones. Vid. Pérez Vidal, Jesús: Estudios de Etnología y Folklore Canario, Santa Cruz de Tenerife, Aula de Cultura de Tenerife, Cabildo de Tenerife, 1985. Galván Tudela, Eduardo: Las fiestas populares canarias, Santa Cruz de Tenerife, Interinsular Canaria, 1987. Bermúdez [Suárez]: Fiesta canaria. Una interpretación teológica, Las Palmas de Gran Canaria, Centro Teológico de Las Palmas, 1991. Santana Jubells, Gustavo: Fiesta y modernidad. Análisis de las transformaciones del sistema festivo en Gran Canaria a finales del siglo XX, Las Palmas de Gran Canaria, Fundación para la Etnografía y el Desarrollo de la Artesanía Canaria (FEDAC), Cabildo de Gran Canaria, 2001. 
como parte integrante de su patrimonio cultural...». A título meramente enunciativo, ofrece once ítems como ejemplos, en los que se incluyen grafismos prehispánicos, tradiciones y expresiones orales que incluye el español de Canarias, el silbo gomero y otras manifestaciones de lenguaje silbado (a); la toponimia actual y la antigua, de la que se recomienda su recuperación en la señalética cuando esté científicamente documentada, con la especificidad del término Canarias (b); las fiestas, competiciones, comidas, representaciones tradicionales populares, con sus sonidos, así como la canaricultura (c); los saberes de la medicina popular (d); conocimientos y usos relacionados con la naturaleza y el cielo (e); aprovechamientos específicos de los paisajes naturales (f); formas de socialización colectiva y organizaciones (g); manifestaciones sonoras, música, representaciones y danza tradicional (h); gastronomía, elaboraciones culinarias y alimentación (i); las técnicas artesanales tradicionales (j); y la técnica de la fotografía minutera (k).

En el artículo 107 se tratan los principios generales que tendrán que ser respetados por los poderes públicos, como el principio de igualdad y no discriminación, protagonismo de las comunidades portadoras, participación con protagonismo de los interesados, dinamismo como patrimonio vivo y por tanto sometido a cambio, sostenibilidad con evitación de alteraciones cualitativas y cuantitativas. El artículo 108 trata del régimen de protección, donde en cuatro puntos se establece la inclusión de los bienes inmateriales en algunos de los instrumentos que establece la ley, de inventario en soporte estable que se puede transmitir al futuro con su investigación y documentación, la obligación de las administraciones públicas en velar por su respeto, conservación y protección, así como que «los medios audiovisuales públicos promoverán el reconocimiento y uso de la modalidad lingüística canaria»5.

Todavía es pronto para valorar la nueva Ley y si realmente la consideración en particular del patrimonio intangible reglamentado en el capítulo $\mathrm{v}$ va a suponer un avance considerable al respecto. Posiblemente, dado el marco estatutario y competencial canario, es bastante probable que existan siete líneas de actuación, tantas como cabildos (gobiernos insulares supramunicipales) que tienen la gestión y la competencia de incoación de expedientes de bienes culturales de su ámbito.

\section{BIENES CULTURALES INTANGIBLES DE CANARIAS}

La relación de los bienes de interés cultural de carácter intangible, de ámbito local o insular, que están declarados en Canarias ofrece un panorama variado, desigual e incompleto en el territorio. En agosto de 2019 son un total de diecisiete, distribuidos en cinco islas, que de mayor a menor número son: Tenerife, 6; La Palma, 5; Gran Canaria, 3; Fuerteventura, 2, y Lanzarote, 1. En el lado contrario, El Hierro, La Gomera y La Graciosa no cuentan con ninguno declarado.

5 Vid. Anexo 1. 
Todas las declaraciones suelen responder a «políticas» y se podría pensar que en nuestro tema, que trata de "política en patrimonio histórico/cultural», se aplica un criterio homogéneo dentro del marco de una misma comunidad autónoma. En efecto, así pudiera ser, pero el modelo competencial canario en esta materia es proclive a una falta de visión global a causa de la descentralización de la gestión. De forma resumida, recordemos que las competencias en el área de cultura fueron transferidas desde el Gobierno de España al Gobierno de Canarias y que determinadas acciones fueron traspasadas desde este a los siete cabildos insulares ${ }^{6}$. En este sentido, el inicio de la instrucción de los expedientes corresponde al Cabildo para el patrimonio ubicado en su ámbito insular, aunque la declaración final es competencia exclusiva del Gobierno de Canarias, en virtud de decreto firmado por el presidente. A todas luces, la lista de los bienes declarados en Canarias es solo un pequeño reflejo del patrimonio intangible canario, ya que incluso revisando por islas, sin quitarle mérito a lo declarado, se aprecian importantes carencias, de las que se expondrán algunos ejemplos.

\section{El Hierro y La Graciosa}

Empezando por las tres islas que carecen de bienes protegidos, La Graciosa es la que menos posibilidades tiene, ya que la isla fue poblada de manera permanente a partir de finales del siglo XIX, siempre muy ligada a Lanzarote. Su característica principal es la fuerte vinculación al mar, ya que por su aridez y escasa extensión carece de agricultura y ganadería, teniendo como recursos la pesca y el turismo especialmente canario. El Hierro sí que cuenta con manifestaciones del más alto interés, siendo la más importante la Bajada de la Virgen de los Reyes, celebrada cada cuatro ańos desde 1741. La imagen de Nuestra Señora es trasladada desde la ermita en el solitario paraje de La Dehesa hasta Santa María de Valverde, villa capital de la isla. Durante el largo recorrido se van incorporando distintas efigies de santos patrones de distintos pagos, cada uno en su «raya», acompañados de los bailarines con sus peculiares atuendos y su percusión de tambores y "pitos», unidos a las loas dedicadas a la «Madre amada». Es una fiesta de gran concurrencia que convoca a miles de herreños que residen fuera de la isla, especialmente en Venezuela, tratándose sin duda de una de las manifestaciones de este tipo más importantes de Canarias. Aunque no se haya declarado de interés cultural, la fiesta de la Bajada de la Virgen sí lo es de interés turístico desde $1980^{8}$. Muy célebres también en El Hierro,

\footnotetext{
${ }^{6}$ La isla de La Graciosa no cuenta con Cabildo y está integrada administrativamente en el Cabildo de Lanzarote y Ayuntamiento de Teguise, municipio emplazado en esa isla.

7 Vid. Cabrera Socorro, Gloria: Los hombres y mujeres de la mar (Isla de La Graciosa), Santa Cruz de Tenerife, Centro de la Cultura Popular Canaria, Cabildo de Lanzarote, 1997.

8 Vid. Anexo III. Vid. López García, Juan Sebastián: «Núcleos y territorialidad históricos de San Miguel de La Palma», Anuario de Estudios Atlánticos, número 38 (1992), pp. 503-523.
} 
en el municipio de Frontera, son los «carneros de Tigaday», donde personas disfrazadas de bestias embadurnan a los espectadores que están presentes en el carnaval ${ }^{9}$.

\section{La Gomera}

Más extraña es la ausencia de La Gomera, que resulta toda una paradoja, ya que cuenta con el único bien canario inscrito como Patrimonio Cultural Inmaterial de la Humanidad (Abu Dhabi, Emiratos Árabes, 30 de septiembre de 2009), que sin duda se trata de la manifestación más valiosa de este tipo en la isla y en Canarias, que ha servido además para detectar este lenguaje en otras islas, como El Hierro $^{10}$. En la nómina de celebraciones gomeras se cuenta con otras que sin tener importancia a nivel mundial, sí que son destacadas en su ámbito. Una de ellas es la fiesta lustral y patronal insular de Nuestra Señora de Guadalupe, romería marítima que zarpa desde la ermita en el aislado paraje de Punta Llana para desembarcar en la playa de San Sebastián de La Gomera, villa capital, donde es recibida y trasladada al templo matriz de Nuestra Señora de la Asunción. En esta celebración no faltan las manifestaciones tan características de la isla como el baile del tambor o tajaraste gomero, acompañado de tambor y chácaras, el romancero gomero, etc. Muy peculiares son también los «ramos» de frutos, flores y verduras, ofrendas que se hacen en varias fiestas de la isla, expresión de gran belleza que fue reflejada en la obra Romería de San Juan, del pintor José Aguiar ${ }^{11}$. No posee eventos declarados de interés turístico, siendo la única isla ausente en ese registro junto con La Graciosa.

\section{Tenerife}

Tenerife es la isla que cuenta con mayor número de bienes protegidos, si integramos en ellos los que se declararon con la categoría de «sitio histórico», aunque en virtud de su carácter inmaterial. De cualquier manera, hay que considerarlos pocos en relación con su potencial. En una lectura rápida de la lista se puede apreciar que solo aparecen cuatro municipios (San Cristóbal de La Laguna, 2; Güimar, 2; La Orotava, 1, y Tegueste, 1; la isla tiene 31), concentrándose la mitad en la comarca aguerera (La Laguna y Tegueste). El más conocido de todos son las alfombras del Corpus Christi de la villa de La Orotava ${ }^{12}$, fiesta religiosa que se celebra

9 Vid. Ávila [Padrón], Ana: Lo humano y lo sacro en la Isla del Hierro, Santa Cruz de Tenerife, Cabildo de El Hierro, Gobierno de Canarias, 1998.

10 Vid. Batista, José Juan, y Morera, Marcial: El silbo gomero. 125 años de estudios lingüisticos y etnográficos, Madrid, Academia Canaria de la Lengua, Gobierno de Canarias.

${ }^{11}$ La obra está en el Salón de Plenos, Cabildo de La Gomera, San Sebastián de La Gomera. Fue realizada en 1924 por el pintor gomero José Aguiar (Santa Clara, Cuba, 1895, bautizado en Agulo, La Gomera, al año siguiente, Madrid, 1976).

12 Alfombras de Corpus, La Orotava: D. 100/2007, de 15 de mayo. 
en su octava; la peculiaridad viene por la confección de artísticas alfombras en el centro histórico con tierras de colores, destacando la que se realiza en la plaza del Ayuntamiento, mientras en las calles predominan las alfombras de flores. El recorrido procesional es de gran brillantez, con obras de arte notables predominando el estilo barroco (custodia en andas de baldaquino, cruces procesionales, ricos ornamentos y otros $)^{13}$.

Si el Corpus orotavense discurre por su conjunto monumental (Bien de Interés Cultural), los demás tienen un carácter menos urbano o se desarrollan en el campo, como es el caso de los localizados en Güímar. En esta ciudad del valle homónimo se cuenta con dos que están declarados con la categoría de sitio histórico, recurso al que podía recurrir en la Ley de 1999 ante la falta de otras concreciones específicas, utilizada en estos casos como lugares donde se desarrollan estas actividades. Ambas declaraciones están vinculadas a la aparición de la imagen de la Virgen de Candelaria en ese menceyato (nombre que llevaban las jurisdicciones prehispánicas de Tenerife), y la devoción mariana en el valle de Güímar, en concreto son el Llano de la Virgen y el Camino del Socorro ${ }^{14}$. Los dos sitios históricos tienen relación entre sí y salvaguardan los lugares donde se desarrollan anualmente manifestaciones intangibles; así, el primero es el llano inmediato a la playa de Chimisay, donde se produjo el hallazgo de la imagen de Nuestra Señora de Candelaria a los guanches, lugar donde se escenifica ese relato, mientras el segundo reconoce el recorrido de la romería de la Virgen del Socorro, cuya imagen es trasladada desde la iglesia matriz de San Pedro Apóstol, pasando por la capilla de San Pedro Abajo hasta la ermita del sitio de El Socorro, parte pues de un ámbito urbano con trayectoria posterior por viejos caminos rurales ${ }^{15}$.

Otros dos bienes se localizan en el municipio de San Cristóbal de La Laguna, aunque no en su casco urbano, declarado Patrimonio de la Humanidad en 1999, sino en otros lugares del municipio, correspondiéndose con los Corazones de Tejina y la Librea de Valle Guerra ${ }^{16}$. Los Corazones están integrados en la fiesta patronal de San Bartolomé Apóstol y constituyen una de las ofrendas más conocidas de Canarias de las que se convierten en decoración festiva, que incluso fueron la primera manifestación intangible que fue reconocida como BIC en las islas ${ }^{17}$. Por su parte, la Librea se celebra el día de Nuestra Seńora del Rosario, patrona del referido pago de Valle Guerra, el sábado más próximo al 7 de octubre, rememorando la batalla

13 Vid. Autores varios: El Tesoro. Catálogo del Museo Sacro de la Parroquia de Ntra. Sra. de La Concepción de La Orotava, Santa Cruz de Tenerife, Gobierno de Canarias.

${ }^{14}$ Llano de la Virgen, sitio histórico, Güímar: D. 50/2009, de 5 de mayo. Camino del Socorro, sitio histórico, Güímar: D. 118/2011, de 17 de mayo.

${ }_{15}$ Para la Virgen de Candelaria Vid. Riquelme Pérez, María Jesús: La Virgen de Candelaria y las Islas Canarias, Santa Cruz de Tenerife, Aula de Cultura de Tenerife, Cabildo de Tenerife, 1990.

${ }_{16}$ Fiesta de los Corazones de Tejina, San Cristóbal de La Laguna: D. 71/2003, de 12 de mayo. La Librea de Valle Guerra, San Cristóbal de La Laguna: D. 132/2007, de 24 de mayo.

17 Vid. Galván Tudela, Alberto y Delgado Domínguez, Erasmo: Los corazones de Tejina, Santa Cruz de Tenerife, Aula de Cultura de Tenerife, Cabildo de Tenerife, 1984. 
de Lepanto (1571), con soldados ataviados de esa época, desfile de barcos, batalla y protagonismo final de la Virgen. Este mismo episodio del reinado de Felipe II también aparece en la Librea de Tegueste ${ }^{18}$, recreada cada cuatro años el 7 de septiembre en honor a Nuestra Señora de los Remedios. Antes se celebraba cada tres años, pero por el alto coste de la misma en 2014 se acordó realizarla cada cuatro en su escenario de la plaza de San Marcos, constando de los siguientes elementos: la milicia, los tres barcos, la danza de las flores y la batalla de los barcos y el castillo, con la presencia de la Virgen, copatrona de Tegueste. Junto con estos bienes, la potencialidad de Tenerife es muy alta; por citar solo unas pocas localidades, daremos los siguientes ejemplos de forma somera: en Puerto de la Cruz destacan los adornos de flores y frutas que se hacen en los «chorros» el día de San Juan Bautista, unido al baño de las cabras en el Muelle Viejo o el «mataculebra» del carnaval; los hachitos de San Juan desde La Vega hasta El Amparo y su tajaraste en Icod de los Vinos, misma ciudad donde están las "tablas de san Andrés», que se deslizan por sus calles de fuerte pendiente; La Laguna con sus fiestas del Cristo ${ }^{19}$ y romería de San Benito Abad, Vilaflor y los itinerarios del santo hermano Pedro (que incluye Granadilla de Abona), el internacional carnaval de Santa Cruz de Tenerife, etc. Como cierre de Tenerife, hay que señalar la singularidad de las dos fiestas que se celebran a la Virgen de Candelaria, patrona de la isla y de la diócesis nivariense, el 2 de febrero (fiesta insular de Tenerife) y el 15 de agosto, especialmente la segunda, que funciona como principal en el ámbito religioso, con la representación de su aparición a los guanches, cuyos descendientes obtuvieron de la Corona el privilegio de portar la imagen. Como información adicional, en esta isla están declarados de interés turístico los siguientes eventos: Fiestas de Carnaval, Santa Cruz de Tenerife (1980), Octava del Corpus y Romería de San Isidro, La Orotava (1980), Romería de San Isidro Labrador, Los Realejos (1980), Romería de San Benito Abad, San Cristóbal de La Laguna (1980), Fiestas de la Santa Cruz, Santa Cruz de Tenerife (1980), Fiesta de la tradición y Romería de San Roque, Garachico (1980), Romería de San Agustín, Arafo (1982), Fiestas de las Cruces y los Fuegos de Mayo, Los Realejos (2012, 2015), Fiestas de los Corazones de Tejina, San Cristóbal de La Laguna (2013), Fiestas de la Florida en honor a San Antonio Abad y Nuestra Señora de la Esperanza, La Orotava $(2018)^{20}$.

${ }^{18}$ La Librea de Tegueste, Tegueste: D. 154/2007, de 5 de junio.

19 Vid. Bonnet y Reverón, Buenaventura: El Santísimo Cristo de La Laguna y su culto, Santa Cruz de Tenerife, Pontificia, Real y Venerable Esclavitud del Santísimo Cristo de La Laguna, Cabildo de Tenerife, 1985. Galante [Gómez], Francisco (dir.): Lumen canariense. El Cristo de La Laguna y su tiempo, tres tomos, Santa Cruz de Tenerife, Ayuntamiento de San Cristóbal de La Laguna, 2003.

$20 \mathrm{Vid}$. Anexo III. 
La Palma cuenta con cinco bienes, que si se tiene en cuenta que todos son oficialmente intangibles (en Tenerife hay dos que son sitios históricos, como se ha visto), sería la isla con el mayor número de ellos. Se podría decir que en el contexto palmero hay cierta diversidad en los tipos de bienes y el reparto geográfico en su territorio se distribuye por varias zonas, en cuatro municipios (El Paso, 2 bienes; Tijarafe, Barlovento y Villa de Mazo con uno) y, en consecuencia, al contar la isla con catorce ayuntamientos, diez carecen de ellos. El Paso es el único municipio palmero que cuenta con dos, uno de ellos está relacionado con una devoción muy arraigada y se corresponde al denominado "Pino de la Virgen ${ }^{21}$, conífera considerada como la más vieja del mundo en su variedad, canariensis, que acoge a su sombra la ermita de Nuestra Señora del Pino, cuya imagen baja cada tres años a El Paso en una vistosa romería. También en esa ciudad está declarada la artesanía de la seda ${ }^{22}$, considerada la única pervivencia europea de elaboración puramente artesanal, contándose con un museo monográfico (Museo de la Seda. Taller las Hilanderas, año 2001). Otro de los bienes está vinculado a Nuestra Señora del Rosario, patrona de la localidad de Barlovento, cuya fiesta rememora la célebre batalla naval mediterránea de 1571 en la denominada "batalla de Lepanto ${ }^{23}$. Se celebra cada tres años, anteriormente en octubre después de la festividad del Rosario, pero por la climatología se pasó al 15 de agosto, contando la misma con los típicos componentes de la nave y el castillo, con un sencillo "diálogo» y lucha entre huestes cristianas y moras, finalizando con la pleitesía a la patrona del municipio. En los otros dos bienes culturales palmeros intangibles está presente un ser que desprende fuego, siendo un espectáculo participativo protagonizado por estos extraños personajes. Desde hace casi cien años, en la localidad de Tijarafe se celebra el 7 de septiembre (víspera de la Natividad de la Virgen) la danza del diablo en honor a Nuestra Señora de la Candelaria ${ }^{24}$, donde el maléfico desprendiendo fuego «aterroriza» a la multitud, aunque finalmente es vencido y huye al son de las campanas que glorifican a María ${ }^{25}$. Por su parte, en el mes de agosto, el borrachito fogatero es un muñeco de trapo con material pirotécnico que es llevado por una persona ${ }^{26}$, e irrumpe al final de distintos elementos en la verbena principal de la fiesta de Nuestra Señora de los Dolores en el pago de Lodero, Villa de Mazo, dando alegría al ambiente.

Por fortuna, La Palma es una isla que ha mantenido buena parte de sus valores culturales tradicionales y en Canarias es reconocida por esos rasgos de identidad, favorecidos al no haber sido la isla objeto de turismo de masas y que al mismo

${ }^{21}$ El Pino de la Virgen, El Paso: D. 124/2014, de 18 de diciembre.

${ }^{22}$ La artesanía de la seda, El Paso: D. 114/2014, de 4 de diciembre.

${ }^{23}$ La Batalla de Lepanto, Barlovento: D. 157/2009, de 15 de diciembre.

${ }^{24}$ La Danza del Diablo, Tijarafe: D. 101/2007, de 15 de mayo.

25 Vid. Noda Gómez, Talio: «La fiesta del diablo de Tijarafe», Aguayro, núm. 172 (1987), pp. 24-25.

${ }^{26}$ El Baile del Borrachito Fogatero, Lodero, Villa de Mazo: D. 115/2014, de 4 de diciembre. 
tiempo el aporte poblacional externo ha sido poco, con lo cual no se ha acentuado el desarraigo ${ }^{27}$. En este sentido, el potencial de patrimonio cultural intangible protegido seguro que se ampliará notablemente. Sin lugar a dudas, el bien inmaterial más importante de La Palma y uno de los más destacados de Canarias es la Bajada de la Virgen de las Nieves, fiesta lustral que conserva un esquema celebrativo del siglo XVIII, enriquecido en las centurias posteriores. Cuenta con actos de gran celebridad en el archipiélago como el «Baile de Enanos» y su famosa polca, tanto que se ha convertido en un icono, aunque no es sino un acto más de los tantos que componen la Bajada, como los Mascarones con el célebre Biscuit, la Pandorga, Romería y traslado del trono de la Virgen, el Carro Alegórico y Triunfal, el diálogo entre el castillo y la nave, las loas, el «minué» o festival del siglo xvin, los acróbatas, etc. Todos estos actos tienen como momento más importante la procesión de Nuestra Señora de las Nieves desde su real santuario hasta la ermita de Nuestra Señora de la Encarnación, desde donde al día siguiente hace la entrada triunfal en la ciudad para quedar entronizada temporalmente en el templo matriz de El Salvador. El complejo programa evidencia, sin detallar descripciones, que es una fiesta singular, tanto que los palmeros y canarios aspiran a que sea declarada Patrimonio de la Humanidad ${ }^{28}$. En otros puntos de la isla se localizan manifestaciones que entendemos menos significativas, pero merecedoras del reconocimiento en el territorio de Canarias, como es el caso del Corpus Christi de la Villa de Mazo, con sus arcos y alfombras de flores, teniendo una gran importancia también en la isla la celebración de la Santa Cruz el 3 de mayo (que también coincide con el aniversario de fundación de la ciudad homónima, que tuvo lugar en esa festividad del año 1493), que incluyen los curiosos «mayos» con sus escenas pintorescas de grandes muñecos de trapo en Santa Cruz de La Palma o las cruces entronizadas, adornadas y enjoyadas en Breña Alta, Breña Baja y $\mathrm{Mazo}^{29}$. Entre otros, también son destacados los «Caballos Fufos» de Tazacorte, una tradición procedente de Cuba a finales del siglo xix y que se bailan con motivo de las fiestas patronales de San Miguel (el arcángel también es patrón de la isla). Igual número de celebraciones están declaradas de interés cultural y de interés turístico, pudiéndose considerar todas de carácter intangible, coincidiendo una de ellas con los bienes culturales ya declarados: Fiestas Lustrales de la Bajada de la Virgen, Santa Cruz de La Palma (1980); Corpus Christi, Villa de Mazo (1986);

27 Vid. Hernández Pérez, María Victoria: La isla de La Palma: las fiestas y tradiciones, La Laguna, Centro de la Cultura Popular Canaria, 2001.

28 Vid. Martino Alba, op. cit., pp. 143-147, Crehuet i Serra, op. cit., pp. 157-159. Henríquez Pérez, Manuel: Opera omnia: la Bajada de la Virgen, la música y La Palma, Breña Alta (La Palma), Cartas Diferentes Ediciones, 2017. Autores varios: I Congreso Internacional de la Bajada de la Virgen (Santa Cruz de La Palma, 27-30 de junio de 2017). Breña Alta, Cartas Diferentes Ediciones, 2017.

${ }^{29}$ BRito DíAz, Carlos: Las Cruces de Mayo en Breña Baja: tradición y arte, Breña Baja, Ilustre Ayuntamiento de la Muy Noble y Honorable Villa de Breńa Baja, 2005. Hernández Pérez, María Victoria: Breña Alta: fiestas de la Cruz, Breña Alta, Ayuntamiento de Breña Alta, 2005. 
Fiesta de la Danza del Diablo, Tijarafe (2012); Semana Santa de Santa Cruz de La Palma (2014); y Fiesta del Entierro de la Sardina de San Andrés y Sauces (2019) ${ }^{30}$.

\section{Gran Canaria}

La tercera isla en cuanto a número de bienes declarados es Gran Canaria, con tres en total, localizados en municipios distintos. Llama la atención que dos tienen el mismo argumento, al tratarse de «bailes de la rama», correspondientes a las que se celebran en Santa María de Guía y en Agaete, el tercer bien se localiza en Las Palmas de Gran Canaria y es de carácter deportivo. La rama de las Marías, en Santa María de Guía ${ }^{31}$, se celebra anualmente el tercer sábado de septiembre en esta ciudad desde el siglo xIX, en relación con la fiesta de las Marías que instituyeron los campesinos por interceder la Virgen en una plaga de langostas. Se baila con ramas en las manos, caracolas, cajas de guerra, tambor y papagüevos, terminando con la ofrenda ante la imagen de la Virgen, que al día siguiente (tercer domingo de septiembre) tendrá la romería y procesión de esa festividad (su celebración patronal es el 15 de agosto), dentro del perímetro de la ciudad ${ }^{32}$. Seguramente la de Guía es la más antigua, distinción que se disputa con la que se celebra cada 4 de agosto en honor de la Virgen de las Nieves en Agaete, la más célebre de las de Canarias, que ya era fiesta de interés turístico nacional desde 1972 cuando se declaró BIC en $2018^{33}$. Al igual que la anterior tiene origen religioso pero ha experimentado cambios notables por la masificación a la que se ha visto sometida en las últimas décadas, tanto que es uno de los actos festivos más concurridos de Canarias. Las ramas se traen desde el monte Tamadaba y partiendo del casco urbano se baila con música de banda y papagüevos hasta el puerto de las Nieves, donde se venera la tabla flamenca de la Virgen homónima, final del recorrido ${ }^{34}$. De distinto carácter es el tercer bien grancanario, perteneciente a un deporte que de forma genérica aparecía protegido en la Ley Canaria de Patrimonio de 1999, pero en este caso está referido en concreto al desarrollo de la vela latina en la ciudad de Las Palmas de Gran Canaria ${ }^{35}$, de mucha tradición en la misma, especialmente en sus barrios costeros.

En Gran Canaria diversas fiestas relativamente recientes han adquirido «carta de identidad» en las últimas décadas e incluso ya en el imaginario colectivo aparecen como "tradicionales», detectándose en muchas de ellas un origen vincu-

30 Vid. Anexo III.

${ }^{31}$ Fiesta de la Rama de las Marías: D. 152/2009, de 1 de diciembre.

32 Vid. Aguiar Castellano, Sergio: Fiesta de las Marias en Guía de Gran Canaria. 200 años de historia de una promesa a la Virgen de Guia (1811-2011), Guía de Gran Canaria, Mayordomos de las Marías, 2011

${ }^{33}$ La Rama de Agaete: D. 43/2018, de 2 de abril.

34 Vid. Godoy Rodríguez, José Antonio: A la sombra del flamboyán, Las Palmas de Gran Canaria, Biblioteca Radio Ecca de Verano, 2010.

${ }^{35}$ La vela latina de Las Palmas de Gran Canaria: D. 43/2016 de 25 de abril. 
lado a las ramas del norte de la isla. Así, por ejemplo, «la traída de agua» en Lomo Magullo (Telde) en las celebraciones en honor a la Virgen de las Nieves, que se repite con variables de otros elementos como «el gofio» en Agüimes (fiestas de la Virgen del Rosario) o «del barro» en La Atalaya de Santa Brígida, que fuera centro «locero». Todas están relacionadas con productos con la intención de darle contenido, habiendo conseguido algunas una gran popularidad. Sin embargo, hay manifestaciones intangibles que tendrían que ser declaradas BIC, como, por ejemplo, la Rama de Santo Domingo de Juncalillo, en Gáldar (segundo sábado de agosto), documentada desde hace más de un siglo, única de este tipo que está localizada dentro del perímetro del paisaje cultural de las montañas sagradas de Gran Canaria, declarado Patrimonio de la Humanidad (Bakú, Azerbaiyán, 7 de julio de 2019). Mucho más conocida, popular y multitudinaria es el célebre "Charco", original "concurso" de pescar lisas el 11 de septiembre en un charco junto a la playa de la Aldea de San Nicolás con motivo de las fiestas patronales de San Nicolás de Tolentino, que también cuentan con una «rama» tradicional. Las alfombras del Corpus Christi en Arucas, el carnaval tradicional de Agüimes, la elaboración artesanal del queso de flor en Guía, Gáldar y Moya, camino de Santiago entre volcanes, etc. Mención aparte, la fiesta insular en honor a Nuestra Señora del Pino, con itinerarios de caminos de fieles que van desde distintos puntos de la isla, con su famosa romería del 7 de septiembre, víspera de la fiesta patronal y de la diócesis, también fiesta insular de Gran Canaria. La imagen tiene bajadas hasta la catedral de Santa Ana, en la ciudad de Las Palmas, pero no son periódicas. Contrastando con las pocas declaraciones de bienes inmateriales que tiene la isla está el número superior de las de interés turístico, aunque no todas son destacadas como patrimonio intangible o existen otras con mejores características para ese rango: Fiestas de Santa Lucía, Santa Lucía (1980), Fiestas en honor de Nuestra Señora de las Nieves, Agaete (1980), Fiestas de Nuestra Señora del Pino, Teror $(1980,2017)$, Fiestas Patronales de Nuestra Señora del Rosario, Agüimes (2002), Fiesta de la manzana, Valleseco (2012), Carnaval de Las Palmas de Gran Canaria (2012, 2017), Fiestas del Almendro en Flor, Tejeda (2014), Festival Internacional de Folklore de la Villa de Ingenio «Muestra Solidaria de los Pueblos», Ingenio (2014) ${ }^{36}$.

\section{Fuerteventura}

Fuerteventura cuenta con dos bienes declarados. Uno de ellos, la Romería de la Virgen de la Peña ${ }^{37}$, aunque su entorno es el santuario de Nuestra Señora de esa advocación, patrona majorera en el pago de Vega de Río Palmas, Betancuria, tiene ámbito insular porque los romeros parten desde los seis municipios de la isla,

36 Vid. Anexo III.

37 Romería de la Virgen de la Peña en la isla de Fuerteventura (todos los municipios: D. 80/2007, de 23 de abril. 
en rutas forjadas desde siglos. De distinto carácter es el segundo bien intangible, que aunque tiene su origen en un hecho bélico no es la famosa batalla de Lepanto, sino la derrota inglesa en su ataque corsario a la isla en 1740 con el triunfo majorero en las batallas de El Cuchillete y Tamasite, lo que determinó que los vecinos de Tuineje hicieran el voto de festejar a su patrón san Miguel en acción de gracias ${ }^{38}$, que actualmente integra una representación del combate. Entre otras manifestaciones destacadas está la rogativa anual a san Andrés para que llueva, con amenaza de despeñarlo si no cumple con el deseo de los fieles, se realiza en Tetir (Puerto del Rosario) y la imagen se traslada en romería desde la iglesia de Santo Domingo a la ermita del apóstol en la montańa de su nombre ${ }^{39}$. Bien intangible de la isla es la misteriosa y esquiva "Luz de Mafasca», muy presente en el imaginario majorero. En cuanto a eventos declarados de interés turístico, Fuerteventura posee dos, las ya citadas fiestas juradas en honor a San Miguel Arcángel Tuineje, BIC en 2007, de interés turístico autonómico (2012) y nacional (2019), mientras el segundo no forma parte del patrimonio inmaterial (Fiestas de la Semana de la Juventud de Gran Tarajal, Tuineje, 2013) ${ }^{40}$.

\section{LANZAROTE}

Finalmente, en este recorrido por Canarias, Lanzarote solo cuenta con un bien declarado, que pone en relación la erupción de 1736 con la devoción a la Virgen de los Dolores, que tras la paralización de la lava en ese enclave se convirtió en patrona de la isla. La categoría de este lugar es la de «sitio histórico» y una cruz recuerda el hecho considerado milagroso ${ }^{41}$, ocurrido en Mancha Blanca, Tinajo. Actualmente la festividad de Los Dolores, también conocida por Virgen de los Volcanes, es la celebración religiosa lanzaroteña más importante y fiesta insular de Lanzarote el 15 de septiembre. Como se ha señalado, su categoría es «sitio histórico», vinculado a un relato emblemático insular. En paralelo y estrictamente inmaterial hay diversas manifestaciones que deberían estar integradas entre los bienes culturales protegidos, algunas muy conocidas y estimadas en Canarias donde destacan las relacionadas con el carnaval, como los «diabletes» de Teguise o las parrandas de buches de Arrecife, con sus distintas y peculiares vestimentas según cada caso. En la villa de Teguise destaca además su célebre Rancho de Pascua y el baile del pastor, con centro en la iglesia de Nuestra Señora de Guadalupe y calles de la villa. Como romería también destaca la de Nuestra Señora de las Nieves, en la montańa de su

${ }^{38}$ Fiestas Juradas de San Miguel Arcángel, Tuineje: D. 102/2007, de 15 de mayo.

39 Vid. López García, Juan Sebastián: «Ritos del agua en Canarias: Artenara, Caideros y Tetir», en Actas del II Congreso Iberoamericano de Antropología (1983), Las Palmas de Gran Canaria, Cabildo de Gran Canaria, 1985, pp. 625-629.

40 Vid. Anexo III.

${ }^{41}$ Lugar marcado por la Cruz, junto a la ermita de los Dolores, sitio histórico, Tinajo: D. $82 / 2003$, de 12 de mayo. 
nombre en el mismo municipio. Posee un evento de interés turístico, las fiestas de San Ginés de Arrecife $(1980)^{42}$.

\section{DOS EJEMPLOS AMERICANOS. LA ANTIGUA GUATEMALA Y GUADALAJARA (MÉXICO)}

\section{Bienes culturales intangibles de La Antigua Guatemala}

Un fenómeno muy frecuente en América fue el de las «ciudades nómadas», que no llegaron hasta su asentamiento actual sino hasta después de varios traslados, uno de esos casos es Santiago de los Caballeros de Guatemala, que actualmente lleva el nombre de La Antigua Guatemala. Fundada en 1524, fue la capital de Centroamérica, sede de la Audiencia, Arzobispado, Universidad y otras instituciones, con una demarcación, que con algunas modificaciones se extendía desde el norte de Panamá hasta Chiapas ${ }^{43}$. El reconocimiento mundial de La Antigua Guatemala, desde el punto de vista de su valor cultural, se produjo en 1979 con su inscripción en la lista de bienes Patrimonio de la Humanidad. La declaración fue por su legado urbanístico y arquitectónico, ubicado en un singular entorno natural, aunque la ciudad posee otra serie de valores que complementan los anteriores, entre los que están el aporte de su acervo inmaterial, que también es exponente y refleja su importante pasado histórico, al mismo tiempo que es un patrimonio vivo. En el caso de La Antigua Guatemala es de destacar que, a pesar del desastre que la ciudad sufrió el 29 de julio de 1773 (terremoto de Santa Marta) y que culminó por decisión de la Corona en 1775 con el traslado de la capital a Nueva Guatemala de la Asunción (más conocida actualmente por Ciudad de Guatemala), pervivió a pesar de los avatares y aún se mantuvo activa en toda esta serie de manifestaciones que perduran hasta hoy.

El patrimonio intangible de La Antigua Guatemala es de una enorme riqueza y constituye un legado sobresaliente que singulariza a la ciudad como prototipo de lugar de patrimonio vivo. La variedad y la calidad de sus manifestaciones inmateriales permiten itinerarios en el tiempo y el espacio que aumentan el valor de Santiago de los Caballeros de Guatemala como una «ciudad patrimonio» en sentido integral. En su conjunto de bienes, es posiblemente el aporte más importante con

42 Vid. Anexo III.

43 Fue fundada el 25 de julio de 1524 en el enclave kaqchikel de Iximché, pero por la hostilidad de los naturales se trasladó a Xepau, luego a Chimaltenango, desde donde pasa al valle de Almolonga, para finalmente emplazarse en el valle del Panchoy en1543. Berdúo, Enrique et alii: Santiago de Guatemala, Hong Kong, López Bruni Editores, 2007, pp. 12-14. Lutz, Christopher H.: Historia sociodemográfica de Santiago de Guatemala, 1541-1773, Guatemala, Centro de Investigaciones Regionales de Mesoamérica (CIRMA), 1984, pp. 38-69. Morales Padrón, Francisco: Atlas histórico cultural de América, II, Las Palmas de Gran Canaria, Consejería de Cultura y Deportes, Gobierno de Canarias, 1988, pp. 407-408, 433, 448-450; Aguilera Rojas, Javier: Antigua. Capital del Reino de Guatemala, Madrid, Ministerio de Educación, Cultura y Deporte, 2002, pp. 63-73. 
el que cuenta la ciudad a la hora de su identidad. Antigua es al mismo tiempo una ciudad patrimonial, con reconocimiento nacional, continental y de la Unesco, y un centro turístico internacional. La presencia del turismo es un arma de doble filo al que se tiene que enfrentar este legado, tanto en su consideración de recurso de atracción ante los visitantes como por lo que se pueda ver afectado por los influjos externos. Por ambas consideraciones, en cuanto a su conocimiento y también en lo relativo a su protección, fue del mayor interés su catalogación entre 2007 y 2011, ya que hasta el momento la atención se había centrado más en su patrimonio inmueble, el urbanismo y la arquitectura, aspectos cuya conservación incluso se había puesto en entredicho por parte de la Unesco. Ante este problema se redactó el Plan Maestro de La Antigua Guatemala, que tuvo en consideración el patrimonio intangible del centro de la ciudad, una vez que se habían catalogado las aldeas con anterioridad ${ }^{44}$.

Las celebraciones inmateriales están presentes a lo largo de todo el año, de manera cíclica, aportando una constante singularidad a La Antigua Guatemala en cualquier mes. Posiblemente el bien del patrimonio intangible antigüeńo más acreditado a nivel mundial sea la Semana Santa, dotada de una gran personalidad. La misma integra una serie de manifestaciones que tienen por escenario tanto los interiores de los templos como diferentes espacios urbanos, calles y plazas, aunque algunas se desplazan de un núcleo a otro. Si bien las procesiones de Cuaresma y Semana Mayor son lo más conocido, todo lo asociado a las mismas forma un conjunto muy notable y señero. Las «velaciones» con los «huertos», las cofradías, las composiciones musicales, las imágenes y sus vestimentas barrocas, tronos, alfombras, etc. En concreto, relacionadas con fechas determinadas a lo largo del año están las cruces de mayo, vinculadas al gremio de los albañiles; las procesiones de las distintas iglesias (Nuestra Señora del Rosario desde el templo de La Merced-Parroquia de San Sebastián, santo hermano Pedro desde San Francisco el Grande, Corpus Christi y los toques de flauta y tambor en la catedral de Santiago-Parroquia de San José, etc.), la fiesta de finados en el cementerio de San Lázaro y la comida de "fiambres», la "quema del diablo» en la celebración de la Inmaculada Concepción, la fiesta patronal de Santiago Apóstol, el Carnaval y los "Cascarones» etc. Mención aparte merece la Navidad con el recorrido de las "posadas» y el «Fin de Año», como expresión de «arte efímero» en los afamados fuegos de artificio, en el marco del Arco de Santa Catalina (Quinta Avenida). Otras manifestaciones como los «toritos de luces», que son una expresión para singularizar determinadas celebraciones o acontecimientos, donde se unen la danza, la pirotecnia y la música, aparte de la artesanía del artilugio. Sin embargo, lo que convierte a La Antigua Guatemala como centro religioso está en relación con la figura del canario santo hermano Pedro de San José Betancurt y el legado tangible e intangible relacionado con él, así está la ruta de pere-

${ }^{44}$ López García, Juan Sebastián: «Proyectos de cooperación/investigación/planificación en La Antigua Guatemala: cursos, catálogo y Plan Maestro de una Ciudad Patrimonio de la Humanidad», en II Jornadas de Arquitectura y Cooperación al desarrollo. Contra el hambre de vivienda ArCaDia II, Las Palmas de Gran Canaria, Universidad de Las Palmas de Gran Canaria, 2014, pp. 63-72. 
grinaje que vincula los lugares de la ciudad que son escenario preferente de su biografía, iglesia y hospital de su fundación (San Pedro), calvario con el esquisúchil, su tumba en San Francisco, etc. Por otra parte están el nomenclátor que resume buena parte de la historia urbana de La Antigua Guatemala, la música popular y solemne, la marimba, la artesanía tradicional, el jade, la comida, los dulces, la multiculturalidad, etc.

Todo este patrimonio urbano se completa con la larga nómina de elementos que están presentes en las aldeas, los cuales -en cierta medida- repiten y complementan el repertorio de bienes intangibles del municipio ${ }^{45}$. Las fichas del catálogo publicado en 2007 sistematizan la información relevante de cada uno de los mismos, con la denominación y ubicación de los bienes, incluyendo también los usos, estado de conservación y la pertinente justificación que razona su inclusión en la nómina de bienes a tener en cuenta. También se determina qué tipo de catalogación posee, así como el grado de protección y las intervenciones que se proponen para salvaguardarlos. Cada ficha recoge la descripción y la fotografía de cada uno de los elementos, así como los demás que le están asociados. Se completa el catálogo con la afección al entorno, las observaciones, el nivel de explotación turística y la bibliografía disponible. Si se hace un rápido recorrido por las distintas aldeas antigüeñas destacarían las velaciones y procesiones de Cuaresma, realizadas en el interior de los templos con sus telones escenográficos (Santa Ana, San Felipe de Jesús, San Cristóbal el Bajo, etc.); «huertos» (aserrín, flores, ramas, frutas, incluso jaulas y acuarios en Santa Ana); los cortejos procesionales por calles y plazas con sus espectaculares tronos, música solemne, alfombras de ramas y flores, etc.; la Romería del Primer Viernes y Sábado de Cuaresma del Señor Sepultado de San Felipe de Jesús con los rosarios de tusa (caparachos); las cruces de Mayo en San Cristóbal el Alto y Santa Isabel Godínez; las distintas fiestas patronales (San Bartolomé Becerra, San Cristóbal Bajo, etc.); el pase y comitiva de fieros enmascarados con cohetes, bombas voladoras, marimba, etc.; los adornos de los cementerios con cintas de colores, flores naturales y artificiales, guirnaldas, la comida de fiambre, música de tambor y flauta, para la celebración de finados; las fogatas frente a las casas que simbolizan la quema del diablo en el comienzo de Navidad. Muy celebrada es la festividad de la Inmaculada Concepción, que cuenta con destacadas manifestaciones en distintas aldeas, así en San Juan del Obispo está el «Rezado de la Concepción», con día principal el domingo intermedio con Navidad, en el que se realiza el desafío de moros y cristianos, loas, quema de pólvora, fieros enmascarados, toritos; mientras en San Pedro Las Huertas se celebra el domingo después de Guadalupe con el «Rezado de Concepción», arcos triunfales, alfombras de pino y flores, torito con su melodía («son del torito»), granadas, loas (popularmente «rezados»), desafíos de moros y cristianos (con

45 Vid. López García, Juan Sebastián; Martín Hernández, Manuel Jesús; Berdúo Samayoa, Carlos Enrique, y Morales Dávila, Héctor Orlando: Catálogo de Bienes Culturales de las Aldeas Circundantes de La Antigua Guatemala, Santa Cruz de Tenerife, Viceconsejería de Emigración, Gobierno de Canarias, 2007. 
jinetes, en otros lugares a pie), músicas, etc.; la Navidad (belenes, alabados y novenario Niño Jesús, etc.) y sus "posadas» con la peculiar música de toques de caparazón de tortuga, chinchines (maracas) y pitos de losa vidriada. Una rica nómina que se completa con el nomenclátor popular (caminos y calles reales, etc.), las alcancías de barro de San Felipe de Jesús, los juegos infantiles tradicionales (maderas torneadas de jacaranda, guitarras, tamborcitos, etc.), la pirotecnia tradicional (granadas de trueno para el día y granadas de luces y trueno para la noche), los mencionados toritos, las músicas popular y solemne (bandas con marimba), comidas tradicionales en las casas, dulces de San Felipe de Jesús, mercados de ventas de comida y frutas, sin olvidar que en todo tienen una enorme importancia las hermandades que promueven la veneración de sus imágenes titulares y «consagradas»: Cristo yacente y Nazareno, Dolorosa y Virgen de la Soledad.

\section{EL «TERritorio inMaterial» DE Guadalajara (MÉXico)}

Hace años planteamos la restauración del territorio aplicado a Canarias, así en 1997 se proponía para la ciudad patrimonial que formó parte de la génesis del sistema urbano del archipiélago una nueva lectura desde el punto de vista humanístico, histórico y territorial «definiendo y jerarquizando las cabeceras históricas e imbricándolas en el sistema regional» ${ }^{46}$. Años después se hizo una aproximación a esta fenomenología aplicando el método a los casos de La Antigua Guatemala y Guadalajara, texto que se tomará como referencia, aunque en este artículo únicamente se tratará el ejemplo mexicano, dado que a la primera se le han dedicado otros $\operatorname{aspectos}^{47}$. De inmediato, ya es sobradamente conocido que Guadalajara y Jalisco se asocian al "carácter» o identidad mexicana, especialmente por dos aspectos, los mariachis y el tequila, aunque en este artículo se planteará un aporte distinto, apoyado en el trabajo referido. Los orígenes de la ciudad son concomitantes con los de La Antigua Guatemala en cuanto que tuvo varios emplazamientos, desde 1532 hasta el definitivo en 1542 en la Guadalajara actual ${ }^{48}$. Su jurisdicción llegó a inte-

\footnotetext{
${ }^{46}$ López García, Juan Sebastián: «La ciudad histórica en Canarias: patrimonio cultural y territorio", Mérida. Ciudady Territorio. Revista Cientifica, n. ${ }^{\circ} 1$ (1997), p. 181.

47 López García, Juan Sebastián: «Ciudad histórica, turismo y revaloración emblemática. Paralelismos entre Guadalajara (Jalisco, México) y La Antigua Guatemala (Sacatepéquez, Guatemala)", en $4 . .^{\circ}$ Coloquio Internacional Ciudades y Turismo, Nuevos Destinos, Guadalajara (México), Universidad de Guadalajara, inédito 2012.

${ }^{48}$ La ciudad fue fundada con título de villa en Nochistlán el 5 de enero de 1532, siguiendo por Tlacotán y Tonalá en 1533, volviendo al segundo emplazamiento en 1535 e instalándose definitivamente con la constitución del Ayuntamiento el 14 de febrero de 1542 en su ubicación actual del valle de Atemajac. Desde 1539 posee el título de ciudad y escudo de armas, otorgados por el emperador Carlos I. Pérez Bourzac, María Teresa: Espacio público e imaginario social, Universidad de Guadalajara, CONACYT, Guadalajara, México 2007, p. 45. Ascencio Rubio, Alfonso: "Centro histórico de Guadalajara: recrear la ciudad histórica», en I Congreso de Patrimonio Histórico, Guadalajara, México, H. Ayuntamiento de Guadalajara, inédito, 2020.
} 
grar el nordeste del actual México y el sudoeste de los Estados Unidos, además del territorio no descubierto o anexionado hacia el norte ${ }^{49}$.

En un repaso muy general, se puede decir que Guadalajara es un lugar rico en cuanto a patrimonio intangible, con reconocimiento mundial, ya que tal como se ha comentado los tópicos de la «mexicanidad» coinciden en mucho con los de la "charrería", los mariachis y el tequila, que aunque ya forman parte del patrimonio de la nación, también lo son en particular de lo tapatío. Sin embargo, el acervo inmaterial es más amplio y difícil de evaluar en una ciudad-metrópoli, donde la sociedad es muy urbana y el mantenimiento de lo ancestral es mucho más difícil que en lugares pequeños por la propia urbanización-globalización y por la heterogeneidad de las personas residentes, aparte de las dificultades que impone la propia escala de la zona metropolitana. Con esto, muchos fenómenos de raíz tradicional pasan a convertirse en espectáculos o recreaciones, por la pérdida de los vínculos sociales de sus orígenes. El propio centro histórico ofrece diariamente oficios y actividades que, reconvertidos en muchos casos, constituyen las manifestaciones intangibles del momento, muchas de ellas "trasladadas» diariamente por las personas desde otros lugares. «Boleros», tejidos tradicionales y artesanías de distinto tipo, las más variadas comidas populares, músicos solistas y grupos de mariachis, campesinos con sus indumentarias, recreación de atuendos precolombinos, las hablas originales, etc., dan vida especialmente a los espacios públicos del entorno de la plaza mayor. También, el peso de la tradición, en cuanto a los toques de campanas o la romería anual de la Virgen de la Expectación de Zapopan o la presencia del «lábaro patrio» en la plaza de la Liberación.

A pesar de lo expuesto como acercamiento a su patrimonio inmaterial, nos vamos a centrar en otro aspecto poco o nada conocido del mismo como es la «territorialidad histórica» de la capital de Jalisco, porque entendemos que es un recurso intangible que forma parte del legado tapatío y que además tiene una tremenda carga de identidad e incluso hasta de marca para su promoción turística. El mayor problema de este patrimonio es su inmaterialidad, aunque algunos de los aspectos de este legado se pueden localizar y vincular a espacios concretos. Para empezar, deberíamos decir que actualmente la «territorialidad histórica de Guadalajara» no existe, al no estar reconocida ni valorada, y aunque es difícil que llegue al nivel de otros bienes que forman parte del potente "carácter» tapatío y de Jalisco (identificado con la mexicanidad), tan presente en el imaginario colectivo de propios y extraños, planteamos ampliar el acervo cultural de la antigua capital de la Nueva Galicia con un elemento más vinculado al centro histórico.

${ }^{49}$ Morales Padrón, op. cit., 1988, iI, pp. 399, 407-408. Su audiencia del siglo Xvi tenía jurisdicción sobre Nueva Galicia, Nueva Vizcaya, Nuevo México y California. Colima, dentro de Nueva Galicia, dependía de México. En la segunda mitad del siglo xviı la audiencia tapatía incluía los gobiernos y capitanías generales de Nueva Galicia, Nueva Vizcaya, Nayarit, California, Sonora y Sinaloa. El obispado fue erigido en 1548 y la Real y Literaria Universidad de Guadalajara, aunque fue solicitada desde 1696, fue creada por Carlos IV en 1791 (Ib., II, pp. 496-499, 535-537). Para Estados Unidos, véanse además $I b$., pp. 208-210, 293-294, 511-514. 
En la América hispana cada ciudad fundada como centro de la administración se dotaba de su territorio, circunstancia por la cual es difícil separar el binomio ciudad-territorio aunque no siempre estuviera delimitado con precisión ${ }^{50}$. Incluso en su carácter de rector territorial, la ciudad mide su importancia por el ámbito de su alcance, tal como indican Hardoy y Aranovich: «La escala de cada ciudad dependería de la fuerza productiva de su área de influencia " ${ }^{51}$ y al respecto, López García afirmaba que

el territorio como construcción histórica tiene un gran valor cultural. En sí, es muy difícil de perfilar, especialmente porque se trata de un patrimonio inmaterial y como tal, depende del grado de valor que se le otorgue. Es un concepto difícil de definir, incluso tendría multiplicidad de enfoques, aunque aquí se le tratará desde uno muy concreto, desde la propia ciudad y su historia. En este caso, la «territorialidad histórica» revela los distintos «alcances» que la ciudad ha tenido en sus funciones a lo largo del tiempo, que lógicamente varían y que hasta se solapan, según el carácter de las mismas, ya que no siempre coincidieron sus jurisdicciones (por ejemplo, el obispado y la audiencia pudieron tener diferentes linderos $)^{52}$.

Con respecto a todo esto en 1987 Francesco Gurrieri trataba el «restauro del territorio», al afirmar: «Il concetto di restauro (cosí come le problematiche della conservaciones monumentale) ha avuto - negli ultimi anni- un trasferimento nella dimensione urbana e territoriale ${ }^{53}$. La consideración de la territorialidad histórica como un valor a tener en cuenta ya está presente en estudios de las últimas décadas del siglo $\mathrm{xx}$, en una tendencia de ampliar y ofrecer varias lecturas del patrimonio cultural, considerándola un descriptor más en las acciones estratégicas en los planes sobre el territorio, en cuanto integrante del acervo cultural, como propusieron López García y Hernández Socorro para Gran Canaria ${ }^{54}$. Con los breves antecedentes expuestos, se puede afirmar que Guadalajara fue la cabecera continental americana más septentrional de la Corona española, más antigua que muchas capitales indianas de república, la más extensa y sin parangón en las tierras situadas en su norte. Pues bien, sin sobrecargar con datos y fechas esta sería la premisa básica que se quiere plantear y que sea identificable con el carácter de Guadalajara como "capital histórica». El antiguo amplio territorio coincidía con la demarcación de su real audiencia (también conocida por el nombre de Nueva Gali-

50 López Guzmán, Rafael: «Ciudades administrativas o de españoles en México (siglo xvi)». Atrio. Revista de Historia del Arte, núms. 10/11, Universidad Pablo de Olavide, Sevilla, 2005, p. 91. $\mathrm{El}$ autor, referido a Centroamérica, habla de «una especie de red que superpuesta al territorio y sobre el entramado de pueblos de indios permitiera el control absoluto de Mesoamérica».

${ }^{51}$ Hardoy, Jorge E., y Aranovich, Carmen: «Escalas y funciones urbanas de la América española hacia 1600. Un ensayo metodológico", en Estudios sobre la ciudad iberoamericana, coordinación de Francisco Solano, Consejo Superior de Investigaciones Científicas, Madrid, 1983, p. 352.

52 López García, op. cit., inédito 2012.

53 Gurrieri, Francesco: «Itinerari del restauro», en Anastilosi. L'antico, il restauro, la città, a cura di Francesco Perego, Roma, Editori Laterza, 1987, p. 7.

54 Vid. López García y Hernández Socorro, op. cit., 1998, pp.1508-1513. 
cia), instituida en 1548 y que sería supranacional, ya que además de por México se extendía por parte de lo que actualmente es Estados Unidos. Cierto es que esa gran extensión cambió de linderos a lo largo de los siglos, pero también que ninguna otra urbe fue reconocida como cabecera de la misma, distinción exclusiva de Guadalajara. En este caso concreto, entendemos que en la ciudad tapatía hay un espacio público que es perfectamente identificable para recuperar la memoria del antiguo territorio jalisciense, con gran capacidad de convocatoria por ser una centralidad conocida por todos, representativa e icónica. Los aspectos indicados concurren en la plaza de Armas, con fuerte arraigo, tanto que a pesar del paso de los siglos no ha perdido su condición de plaza mayor y además constituye uno de los elementos más destacados y reconocidos de la identidad colectiva. Ya es un recinto emblemático, pero se puede dotar de más contenidos en su valor cultural e identitario en el ámbito del patrimonio intangible, resaltándose todo su potencial histórico, fundamentado en lo inmueble de su urbanismo, arquitectura y arte. En concreto, ese entorno era el centro administrativo de poder desde donde se organizaba el territorio dependiente de Guadalajara, cuya imagen sería la plaza como espacio público y el antiguo palacio de la audiencia como lugar del gobierno del amplio ámbito geográfico. Por tanto, no son iconos limitados a la propia ciudad y al estado de Jalisco, sino que en una relectura ampliarían su significado con la connotación cultural de algo que pertenece a la historia común de lo que hoy son parte de dos países soberanos diferentes que comparten páginas de los anales. En su condición particular de pertenencia al patrimonio inmaterial tapatío puede ser reconocible precisamente en esta plaza como espacio-tiempo recuperado para la memoria de los pueblos. Unos paneles informativos pueden ofrecer esta relectura de la plaza de Armas explicando su significado más allá de lo que se ve: desde la ciudad con su arquitectura se incorpora la territorialidad histórica como un bien intangible más del patrimonio inmaterial tapatío.

\section{CONCLUSIONES}

La tendencia actual otorga cada vez una mayor valoración al patrimonio intangible, posiblemente por la convicción de su vulnerabilidad y que en estos momentos de cambio está sometido a distintas presiones externas y circunstancias internas que hacen peligrar su integridad, tales como serían las influencias de medios ajenos (halloween o "noche de las brujas» contra los finados o fiesta de los muertos) o las circunstancias de las comunidades (éxodo rural, recambios generacionales, etc.), unido al considerarlo un recurso turístico, lo que conlleva el peligro que se pudiera ir adaptando a los gustos de los clientes para que sea rentable en el mercado.

La consideración de los bienes intangibles en la nueva Ley de Patrimonio Cultural de Canarias es una oportunidad de reflexión sobre un tema que hasta el momento se presenta incompleto y desordenado en el archipiélago. A pesar de ser una ley común para toda la comunidad autónoma, es más que probable que los efectos prácticos de la misma sean diferentes, ya que su aplicación en cada isla depende del Cabildo o gobierno supramunicipal correspondiente, que es el competente en 
la gestión del patrimonio histórico de su ámbito. Una circunstancia que manifiesta claramente las desigualdades entre islas y hasta las distintas orientaciones insulares es la relación de bienes declarados en cada una de ellas, donde incluso algunas carecen de los mismos.

Por el tipo de economía isleńa, casi monopolizada por la «industria turística», ha calado fuertemente en la colectividad que estas manifestaciones son más de interés y del ámbito turístico, con lo cual se detecta que muchos elementos se han promocionado con este enfoque y celebraciones que claramente son de carácter intangible aparecen en esos registros y no entre los bienes culturales ( $V i d$. Anexo III. xxx), de tal manera que frente a 28 de interés turístico se registran 17 de interés cultu$\mathrm{ral}$. Desde las consideraciones generales en Canarias es positivo establecer los cotejos con lo americano, del que en este trabajo se han tomado dos ejemplos, uno en el sentido más amplio en lo tradicional y otro menos convencional, tal como es la «recuperación» territorial; ambos planteamientos se complementan y sirven para fomentar relaciones en el ámbito internacional hispano (una antigüeńa/guatemalteca y otra tapatía/mexicana). Ha sido interesante exponer consideraciones correspondientes a distintos lugares, aunque el muestreo fuera escaso, ya que sirve para contrastar y constatar diferencias y analogías entre ámbitos geográficos y se podría decir que en esas variedades del legado radica lo que se puede definir por antonomasia como "lo propio» en materia de patrimonio intangible. América constituye para Canarias un referente no solo metodológico sino también documental, al dar respuesta a cuestiones que se plantean en el archipiélago especialmente desde los lugares del continente con los que las islas han tenido sus mayores vínculos humanos a lo largo de la historia, por la emigración canaria a América, especialmente Cuba.

Igual que en los bienes referidos al patrimonio intangible antigüeño, la mayoría del canario está en relación con manifestaciones de ciclo anual. En los bienes declarados de interés cultural en Canarias hay una variedad de los mismos, tanto de los que se pueden considerar como un "espectáculo" para ser visto como los que permiten una "participación" activa y directa en su desarrollo. Entre los primeros estarían bienes representados por las «Libreas» y la «Batalla de Lepanto», mientras en los segundos estarían los que son protagonizados por «extraños personajes» como el borrachito o el diablo que se moverán entre la multitud para provocar una interacción. El actual catálogo incluye también relictos de técnicas antiguas perdidas en otros lugares (la seda), manifestaciones de arte efímero (alfombras de Corpus Christi y los corazones), bailes y ofrendas (las ramas y romerías), lugares relacionados con relatos milagrosos (apariciones de imágenes), etc. En paralelo, habría que retomar el espíritu de un proyecto de finales del siglo xx (el plan estratégico Gran Canaria Siglo XXI), donde se proponía recuperar de alguna manera la territorialidad histórica de esa isla a partir de un mayor protagonismo de sus dos cabeceras canarias antiguas (Gáldar y Telde). La Ley no trata en sí este aspecto, pero alude a la recuperación de la toponimia prehispánica que esté debidamente documentada y reconocida, aunque desde este trabajo se propone considerar además la territorialidad como bien intangible, al ser el origen del proceso que ha derivado en la situación administrativa actual, donde incluso se manifiesta a partir de un legado diverso, enrique- 
cido a lo largo de los siglos, en el ámbito de lo simbólico y emblemático en virtud de una relectura que ofrezca una nueva visión de los elementos culturales tangibles.

Como un valor cada vez más estimado, este trabajo descriptivo, analítico y comparativo trata de dar una visión general y divulgativa del patrimonio intangible canario, sintetizando una situación concreta y aclarando las tendencias actuales que permiten ver el enfoque que se ha tenido en las políticas culturales de esta materia. El resultado es muy disperso e incompleto, si se quiere hasta confuso, lo que pone en evidencia que muchos bienes han sido primero considerados de interés turístico y no cultural, situación que seguramente será reversible en los próximos años, con lo cual muchos elementos que ahora solo son tenidos en cuenta como un recurso para los visitantes se retomarán como integrantes del legado de identidad.

En suma, la potencialidad de estos bienes es muy grande en todos los aspectos y en su relación con el territorio, los centros históricos, el patrimonio etnográfico, la arquitectura, el arte, etc. Está presente en los espacios públicos y en los privados, en la imagen permanente y en la cambiante, en los ambientes, sabores y olores, en lo que da color a los lugares, en lo repetitivo de los calendarios con la cohesión de la sociedad y las comunidades, en la urgencia de documentar los saberes que se van con las personas. Un mundo patrimonial muy grande y difícil de abarcar, por eso mismo, por ser inmaterial, efímero e intangible. 


\section{ANEXO I}

Ley 11/2019, de 25 de abril, de Patrimonio Cultural de Canarias

BOC, núm. 90, lunes 13 de mayo de 2019.

Capítulo V. Patrimonio inmaterial. Artículo 106.- Concepto

Tendrán la consideración de patrimonio cultural inmaterial los usos, represtaciones, expresiones, conocimientos y técnicas que las comunidades, los grupos, y, en algunos casos, los individuos reconozcan como parte integrante de su patrimonio cultural y, en particular, a título meramente enunciativo, los siguientes:

a) Las tradiciones y expresiones orales, incluidas las modalidades y particularidades lingüísticas del español de Canarias, la terminología y grafismos de origen aborigen, el silbo gomero y otras manifestaciones del lenguaje silbado, refranes, poemas, décimas, leyendas, así como sus formas de expresión y transmisión.

b) La toponimia tradicional, como instrumento para la concreción de la denominación geográfica de los territorios, así como el término «Canarias» en sentido amplio y la terminología que de él derive.

La toponimia aborigen científicamente admitida que no sea de uso habitual se procurará que figure junto a la actual señalética de carreteras.

c) Las manifestaciones festivas, competitivas, gastronómicas, lúdicas y recreativas, así como sus representaciones tradicionales y populares, con sus correspondientes instrumentos, útiles y complementos, así como la canaricultura como actividad competitiva, social y cultural autóctona y tradicional.

d) Los conocimientos y usos relacionados con la naturaleza y el universo.

e) El aprovechamiento de los saberes relacionados con la medicina popular.

f) El aprovechamiento de los paisajes naturales.

g) Las formas de socialización colectiva y organizaciones.

h) Las manifestaciones sonoras, música y danza tradicionales, así como sus representaciones tradicionales y populares, con sus correspondientes instrumentos, útiles y complementos.

i) Las técnicas artesanales tradicionales.

j) La técnica de la fotografía minutera.

k) La gastronomía, elaboraciones culinarias y alimentación.

\section{Artículo 107.- Principios generales}

Las actuaciones de los poderes públicos sobre los bienes de patrimonio inmaterial que sean objeto de salvaguarda deberán respetar, en su preparación y desarrollo, los siguientes principios generales:

a) El principio de igualdad y no discriminación, garantizando la participación más amplia posible de la diversidad de mujeres y hombres en los procesos de 
toma de decisiones sobre la definición, la conservación, la transmisión, la recreación y la gestión del patrimonio cultural, atendiendo a la estructuración simultánea de las desigualdades de género y otras desigualdades sociales en función de la clase, la etnia, la edad, entre otras.

b) El protagonismo de las comunidades portadoras, como titulares, mantenedoras y legítimas usuarias del mismo.

c) El principio de participación, con el objeto de mantener e impulsar el protagonismo de los grupos, comunidades portadoras, organizaciones y asociaciones ciudadanas en la recreación, transmisión y difusión del mismo.

d) El dinamismo inherente al patrimonio cultural inmaterial, que por naturaleza es un patrimonio vivo, que responde a prácticas en continuo cambio.

e) La sostenibilidad de las manifestaciones culturales inmateriales, evitándose las alteraciones cuantitativas y cualitativas de los elementos culturales ajenas a las comunidades portadoras y gestoras de las mismas.

\section{Artículo 108.- Régimen de protección}

1. La protección de los bienes que integran el patrimonio inmaterial se llevará a cabo la inclusión en alguno de los instrumentos previstos en esta ley.

2. Los bienes integrantes de patrimonio cultural inmaterial se recopilarán e inventariarán en soportes estables que posibiliten su transmisión a las generaciones futuras, promoviendo para ello su investigación y documentación.

3. Las administraciones públicas velarán por el respeto, la conservación y la protección del patrimonio cultural inmaterial mediante su promoción, difusión, estudio y recopilación.

4. Los medios audiovisuales públicos promoverán el reconocimiento y uso de la modalidad lingüística canaria. 


\section{ANEXO II}

Bienes de Interés Cultural de Carácter inMaterial, de Ámbito local o INSULAR

Fuente: Gobierno de Canarias. Orden cronológico

- Fiesta de los Corazones de Tejina, San Cristóbal de La Laguna (Tf): D. 71/2003, de 12 de mayo.

- Lugar marcado por la Cruz, junto a la Ermita de los Dolores, sitio histórico, Tinajo (Lz): D. 82/2003, de 12 de mayo.

- Romería de la Virgen de la Peña (todos los municipios) (Fv): D. 80/2007, de 23 de abril.

- Alfombras de Corpus, La Orotava (Tf): D. 100/2007, de 15 de mayo.

- La Danza del Diablo, Tijarafe (LP): D. 101/2007, de 15 de mayo.

- Fiestas Juradas de San Miguel Arcángel, Tuineje (Fv): D. 102/2007, de 15 de mayo.

- La Librea de Valle Guerra, San Cristóbal de La Laguna (Tf): D. 132/2007, de 24 de mayo.

- La Librea de Tegueste, Tegueste (Tf): D. 154/2007, de 5 de junio.

- Llano de la Virgen, sitio histórico, Güímar (Tf): D. 50/2009, de 5 de mayo.

- Fiesta de la Rama de las Marías, Santa María de Guía (GC): D. 152/2009, de 1 de diciembre.

- La Batalla de Lepanto, Barlovento (LP): D. 157/2009, de 15 de diciembre.

- Camino del Socorro, sitio histórico, Güímar (Tf): D. 118/2011, de 17 de mayo

- La artesanía de la seda, El Paso (LP): D. 114/2014, de 4 de diciembre.

- El Baile del Borrachito Fogatero, Lodero, Villa de Mazo (LP): D. 115/2014, de 4 de diciembre.

- El Pino de la Virgen, El Paso (LP): D. 124/2014, de 18 de diciembre

- La Vela Latina de Las Palmas de Gran Canaria (GC): D. 43/2016 de 25 de abril

- La Rama de Agaete, Agaete (GC): D. 43/2018, de 2 de abril. 


\section{ANEXO III}

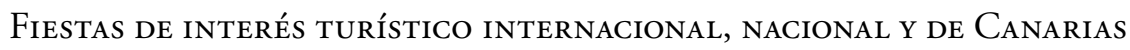

Fuente: Gobierno de Canarias. Orden cronológico

- Fiestas de Carnaval, Santa Cruz de Tenerife (Tf) (internacional): BOE 16/02/1980.

- Fiestas Lustrales de la Bajada de la Virgen, Santa Cruz de La Palma (LP): $B O E$ 16/02/1980.

- Octava del Corpus y Romería de San Isidro, La Orotava (Tf): BOE 16/02/1980.

- Romería de San Isidro Labrador, Los Realejos (Tf): BOE 16/02/1980.

- Romería de San Benito Abad, San Cristóbal de La Laguna (Tf): BOE 16/02/1980.

- Fiestas de la Santa Cruz, Santa Cruz de Tenerife (Tf): BOE 16/02/1980.

- Fiestas de la Bajada de la Virgen, Valverde (EH): BOE 16/02/1980.

- Fiestas de San Ginés, Arrecife (Lz): BOE 18/02/1980.

- Fiestas de Santa Lucía, Santa Lucía (GC): BOE 18/02/1980.

- Fiestas en honor de Nuestra Señora de las Nieves, Agaete (GC): BOE 18/02/1980.

- Fiestas de Nuestra Señora del Pino, Teror (GC): BOE 18/02/1980.

- Fiesta de la tradición y Romería de San Roque, Garachico (Tf): BOE 18/02/1980.

- Romería de San Agustín, Arafo (Tf): BOE 25/11/1982.

- Corpus Christi, Villa de Mazo (LP): BOE 14/01/1986.

- Fiestas Patronales de Nuestra Señora del Rosario, Agüimes (GC): BOE 29/10/2002.

- Fiesta de la manzana, Valleseco (GC): BOC 18/09/2012.

- Carnaval de Las Palmas de Gran Canaria (GC): BOC 18/09/2012 y BOE $31 / 03 / 2017$.

- Fiestas de las Cruces y los Fuegos de Mayo, Los Realejos (Tf): BOC 18/09/2012 y BOE 10/04/2015.

- Fiesta de la Danza del Diablo, Tijarafe (LP): BOC 18/09/2012.

- Fiestas Juradas en honor a San Miguel Arcángel, Tuineje (Fv): BOC 18/09/2012 y $B O E 10 / 06 / 2019$.

- Fiestas de los Corazones de Tejina, San Cristóbal de La Laguna (Tf): BOC 22/10/2013.

- Fiestas de la Semana de la Juventud de Gran Tarajal, Tuineje (Fv): BOC 22/10/2013.

- Fiestas del Almendro en Flor, Tejeda (GC): BOC 23/01/2014.

- Semana Santa de Santa Cruz de La Palma, Santa Cruz de La Palma (LP): BOC 05/03/2014. 
- Festival Internacional de Folklore de la Villa de Ingenio «Muestra Solidaria de los Pueblos», Ingenio (GC): BOC 03/07/2014.

- Fiestas del Pino, Teror (GC): BOC 07/04/2017.

- Fiestas de la Florida en honor a San Antonio Abad y Nuestra Señora de la Esperanza, La Orotava (Tf): BOC 18/07/2018.

- Fiesta del Entierro de la Sardina de San Andrés y Sauces, San Andrés y Sauces (LP): BOC 04/06/2019.

Siglas de islas: EH (El Hierro). Fv (Fuerteventura), GC (Gran Canaria), LP (La Palmas), Lz (Lanzarote), Tf (Tenerife). La Gomera y La Graciosa no cuentan con declaraciones. 